\title{
Composição florística de pastagem natural afetada por fontes de fósforo, calagem e introdução de espécies forrageiras de estação fria ${ }^{1}$
}

\author{
Botanical composition of natural pasture as afected by phosphorus sources, \\ lime and introduction of winter forage species
}

\author{
Duilio Guerra Bandinelli ${ }^{2}$ Luciano Colpo Gatiboni ${ }^{3}$ José Pedro Pereira Trindade $^{4}$ \\ Fernando Luiz Ferreira de Quadros ${ }^{5}$ João Kaminski ${ }^{5}$ João Paulo Cassol Flores ${ }^{6}$ \\ Gustavo Brunetto ${ }^{6}$ Adair Saggin ${ }^{6}$
}

\section{RESUMO}

Uma das características das pastagens naturais do Rio Grande do Sul é a baixa produtividade de forragem no período do outono-inverno. Uma das alternativas para melhorar os sistemas de produção baseados nessas pastagens é a introdução de espécies forrageiras de crescimento invernoprimaveril e a fertilização e correção da acidez do solo. $O$ presente trabalho teve por objetivo avaliar o efeito de fontes de fósforo, calcário e introdução de espécies forrageiras de inverno na dinâmica das espécies de uma pastagem natural. Os tratamentos testados foram: T1 - superfosfato simples + calcário + introdução de espécies; T2 - superfosfato triplo + calcário + introdução de espécies; T3 - superfosfato triplo + introdução de espécies; T4 - hiperfosfato de Gafsa + introdução de espécies; T5 - introdução de espécies sem fósforo ou calagem; T6 testemunha com pastagem natural. Para a avaliação da composição florística da pastagem foram realizados levantamentos botânicos periódicos, durante vinte e dois meses, utilizando-se o método BOTANAL. Os resultados mostraram que os tratamentos testados não provocaram mudanças na composição botânica das espécies nativas no período de tempo avaliado.

Palavras-chave: composição botânica, pastagem natural, fósforo, calagem, melhoramento.

\section{ABSTRACT}

Natural pastures of Rio Grande do Sul State, South of Brazil, have low forage productivity in the autumn-winter. An

\begin{abstract}
alternative to improve systems based on these pastures is introduction of winter forage species, fertilization and liming of soil. The present work had the objective of evaluating the effect of phosphorus sources, lime and introduction of winter forage species in the pasture botanical composition dynamics. The treatments used were: $T 1$ - simple superphosphate + lime + winter forage species introduction; T2 - triple superphosphate + lime + winter forage species introduction; T3 - triple superphosphate + winter forage species introduction; T4 - Gafsa rock phosphate + winter forage species introduction; T5 - winter forage species introduction without phosphorus and lime; T6 - reference only with natural pasture. To evaluate the botanical composition dynamics, periodic botanical evaluations were done during twenty two months, using BOTANAL method. The results showed that treatments did not modify the botanical composition of natural pasture during the evaluation period.
\end{abstract}

Key words: botanical composition, natural pasture, phosphorus, lime, improvement.

\section{INTRODUÇÃO}

No Rio Grande do Sul (RS), as pastagens naturais, também chamadas de campos nativos, ocupam uma área de 10,5 milhões de hectares, o que representa 43\% da área do Estado (IBGE, 1996). BOLDRINI (1997), em levantamentos botânicos realizados nestas pastagens, registrou 450 espécies de

${ }^{1}$ Parte da dissertação de mestrado do segundo autor

${ }^{2}$ Engenheiro Agrônomo, Aluno do Curso de Pós-graduação em Zootecnia, Universidade Federal de Santa Maria (UFSM), Santa Maria, RS. Bolsista da Coordenação de Aperfeiçoamento de Pessoal de Ensino Superior (CAPES). E-mail: bandlli@ zipmail.com.br ${ }^{3}$ Engenheiro Agrônomo, Doutor, Centro de Ciências Rurais, UFSM, 97105-900, Santa Maria, RS. E-mail gatiboni@uol.com.br. Autor para correspondência.

${ }^{4}$ Engenheiro Agrônomo, Bolsista de Pós-Doutorado do Conselho Nacional de Desenvolvimento Científico e Tecnológico (CNPq).

${ }^{5}$ Engenheiro Agrônomo, Doutor, Professor do Centro de Ciências Rurais da UFSM, 97105-900, Santa Maria, RS

${ }^{6}$ Engenheiro Agrônomo, Aluno do Curso de Pós-graduação em Ciência do Solo, Universidade Federal do Rio Grande do Sul (UFRGS), Porto Alegre, RS e UFSM, RS. Bolsista CAPES 
gramíneas e 150 espécies de leguminosas, a maioria delas perenes e de crescimento estival, o que lhes confere boa oferta de forragem na estação quente e reduzida oferta na estação fria. Para aumentar a produtividade deste sistema, pode-se introduzir espécies forrageiras de crescimento hibernal no campo nativo, que visa ao aumento de produção de forragem no período hiberno-primaveril, proporcionando uma produção de forragem em maior quantidade e qualidade nutricional nesta época crítica (CARÁMBULA, 1997).

Um ponto importante para o sucesso do melhoramento de pastagens naturais é a escolha das espécies adequadas para a introdução (CARÁMBULA, 1997). Como os solos sob pastagens naturais do RS são limitantes em nutrientes, principalmente fósforo, e, por vezes, ácidos (NABINGER, 1980; RHEINHEIMER et al., 2001), há necessidade de aplicação de fertilizantes e correção da acidez do solo para o sucesso da implantação das espécies exóticas na pastagem natural. Respostas das pastagens naturais à adubação fosfatada após a introdução de espécies são encontradas mais freqüentemente do que respostas à adição de calcário, porque o fósforo limita mais a produção que a acidez do solo, como observado por MACEDO \& GONÇALVES (1980), MACEDO et al. (1985), GATIBONI et al. (2000) e GATIBONI et al. (2003). Já respostas das pastagens à adubação potássica são raras porque a maioria dos solos do RS possui níveis de médio a suficiente desse nutriente (RHEINHEIMER et al., 2001).

As alterações provocadas no ambiente pela adubação, calagem e introdução de espécies, têm conseqüências sobre a composição botânica da pastagem natural, sendo normalmente observada diminuição da participação de espécies naturais como Vernonia sp., Baccharis sp., Schizachyrium microstachyum e Eryngium sp. (FONTANELI \& JACQUES, 1986; SILVA \& JACQUES, 1993; CASTILHOS \& JACQUES, 2000) e, por vezes, aumento de espécies como Paspalum notatum, como observado por FONTANELI \& JACQUES (1986) e GOMES et al. (1998). Porém, BARRETO et al. (1986) alertam que, para o manejo, principalmente a adubação, afetar a composição botânica da pastagem natural, são necessários alguns anos para a readaptação da vegetação.

Este trabalho objetivou avaliar o efeito da introdução de espécies forrageiras de inverno e de diferentes tipos de adubos fosfatados, associados ou não à calagem, sobre a dinâmica da composição florística da pastagem natural.

\section{MATERIAL E MÉTODOS}

O experimento foi conduzido no campus da UFSM-RS, localizada na região fisiográfica denominada Depressão Central, com altitude média de $95 \mathrm{~m}$, latitude $29^{\circ} 43^{\prime}$ Sul e longitude $53^{\circ} 42^{\prime}$ a Oeste de Greenwich. O clima, segundo a classificação de Köppen é Cfa - subtropical úmido, com precipitação pluviométrica e temperatura média anuais de $1769 \mathrm{~mm}$ e $19,2^{\circ} \mathrm{C}$, respectivamente, com ocorrência de geadas nos meses de maio a agosto.

O solo utilizado é um Argissolo Vermelho distrófico típico (STRECK et al., 2002), com textura superficial arenosa, sendo que a análise química realizada antes do início do experimento indicou os seguintes valores para: $\mathrm{pH}-\mathrm{H}_{2} \mathrm{O}=4,5$; Índice $\mathrm{SMP}=5,6$; M.O. $=18 \mathrm{~g} \mathrm{~kg}^{-1}$; Argila $=170 \mathrm{~kg}^{-1}, \mathrm{P}=2,5 \mathrm{mg} \mathrm{kg}{ }^{-1}$; $\mathrm{K}=60 \mathrm{mg} \mathrm{kg}^{-1} ; \mathrm{Ca}=1,17 \mathrm{cmol}_{\mathrm{c}} \mathrm{kg}^{-1} ; \mathrm{Mg}=, 75 \mathrm{cmol}_{\mathrm{c}} \mathrm{kg}^{-1}$ e $\mathrm{Al}=1,3 \mathrm{cmol}_{\mathrm{c}} \mathrm{kg}^{-1}$. A contribuição percentual média na massa seca (MS) total das principais espécies nativas observadas antes da introdução das espécies exóticas (06/02 e 16/05/97), foi constituída por $\boldsymbol{P}$. notatum (45,3); Eryngium ciliatum (21,2); Andropogon ternatus $(1,0) ; \boldsymbol{P}$. plicatulum $(0,5)$; Choloris polydactyla e $\boldsymbol{S}$. microstachyum $(0,3) ; \boldsymbol{E}$. horridum, Aristida laevis, Piptochaetium montevidensis e Erianthus sp. (0,2), com elevada incidência do componente material morto $(29,2 \%)$. O manejo da pastagem, antes da instalação do experimento, constituía-se de roçadas sucessivas, sempre que a vegetação ultrapassasse 20 a $30 \mathrm{~cm}$ de altura.

Os tratamentos foram arranjados no delineamento experimental de blocos ao acaso com quatro repetições e consistiram na utilização de fontes de fósforo com ou sem associação com calcário e introdução de azevém (Lolium multiflorum cv. comum) e trevo vesiculoso (Trifolium vesiculosum cv. Yuchi) sobre a pastagem natural. Os tratamentos foram: T1- superfosfato simples (SFS) + calcário + introdução de espécies (IE); T2- superfosfato triplo (SFT) + calcário + IE; T3- superfosfato triplo + IE; T4- hiperfosfato de Gafsa + IE; T5- IE sem fósforo ou calagem; T6- testemunha com pastagem natural.

A semeadura ocorreu em 30/05/1997 e foi realizada com semeadora de plantio direto sobre a pastagem natural sem dessecação prévia com herbicidas, sendo utilizadas sementes de azevém e trevo vesiculoso nas quantidades de 30 e $12 \mathrm{~kg} \mathrm{ha}^{-1}$, respectivamente. Os fertilizantes foram aplicados superficialmente, por ocasião da semeadura e as doses de fertilizantes fosfatados e calcário utilizadas seguiram a recomendação da COMISSÃO DE 
FERTILIDADE DO SOLO - RS/SC (1994), sendo $150 \mathrm{~kg} \mathrm{ha}^{-1}$ de $\mathrm{P}_{2} \mathrm{O}_{5}$ e $3,2 \mathrm{t} \mathrm{ha} \mathrm{a}^{-1}$ de calcário dolomítico (1/2 da dose para elevar o $\mathrm{pH}$ a 5,5). Em todos os tratamentos com IE (T1, T2, T3, T4 e T5) também foram adicionados $180 \mathrm{~kg} \mathrm{ha}^{-1}$ de $\mathrm{K}_{2} \mathrm{O}$ no momento da semeadura e duas adubações de cobertura com uréia, de 40 e $30 \mathrm{~kg} \mathrm{ha}^{-1}$ de $\mathrm{N}$, aos 40 e 70 dias após a semeadura. Uma nova ressemeadura de ambas espécies foi realizada no segundo ano (junho/98), porque o regime de cortes imposto no primeiro ano não permitiu a ressemeadura natural das espécies.

Para monitorar a composição florística das espécies da pastagem foram realizados seis levantamentos botânicos $(06 / 02 ; 16 / 05 ; 15 / 09 ; 27 / 11 /$ 97; 02/04 e 25/11/98), em datas próximas às avaliações de produção de MS, utilizando-se o método BOTANAL, descrito por TOTHILL et al. (1992), sendo utilizadas três repetições por parcela, em quadros fixos de $0,25 \mathrm{~m}^{2}$, marcados previamente ao início do experimento. Para determinação da MS foram realizados cortes a $5,0 \mathrm{~cm}$ de altura e a percentagem de participação dos componentes pastagem natural (todas espécies nativas agrupadas), azevém e trevo vesiculoso foi estimada visualmente no momento do corte. Após cada corte, a área foi roçada e o material cortado retirado da área.

Os dados de contribuição percentual de espécies e do componente material morto na composição botânica estacional foram submetidos à análise multivariada de ordenação, pelo método de coordenadas principais, com distância euclidiana como medida de semelhança (PODANI, 1994), utilizando o programa MULTIV (PILLAR, 1997).

\section{RESULTADOS E DISCUSSÃO}

A produção de MS e, sua resposta aos tratamentos foi abordada em GATIBONI et al. (2000), os quais mostraram que a maior produtividade total de forragem foi obtida com o tratamento SFS + calcário, sendo superior aos tratamentos SFT + calcário e SFT, que não diferiram entre si, indicando que a pastagem não respondeu à calagem. Assim, a maior produtividade do tratamento SFS + calcário foi atribuída ao enxofre contido no SFS, que poderia ser um fator limitante no solo. $\mathrm{O}$ tratamento com adição de fosfato natural (hiperfosfato de Gafsa) apresentou menor produtividade do que os com adição de fosfatos solúveis, porém maior que os tratamentos sem adição de fósforo, mostrando que o fosfato natural disponibilizou apenas parte de seu conteúdo de fósforo para as plantas. Os resultados de GATIBONI et al. (2000) mostraram ainda que, quando os componentes da forragem foram separados, a pastagem natural respondeu pouco aos tratamentos, mas a produção de azevém foi afetada pelo fósforo e a produção de trevo vesiculoso foi afetada, além do fósforo, pela correção da acidez do solo.

Na figura 1, é apresentada a participação percentual dos componentes: pastagem natural, azevém e trevo vesiculoso na MS produzida no período de 16/05/1997 a 26/11/1998, estimada em cinco cortes da forragem. A figura 1 mostra que nos tratamentos com aplicação de fontes de fósforo a elevada participação das espécies introduzidas, azevém (mai-nov/97) e trevo vesiculoso (abr-nov/98) no tratamento SFS + calcário, principalmente, propiciaram a redução na participação percentual da pastagem natural na MS produzida, indicando que esta redução foi devida à competição exercida pelas espécies introduzidas, as quais foram os principais contribuintes para a produção de forragem nos respectivos tratamentos e períodos (Figura 2). Efeitos semelhantes desta competição foram observados por SCHOLL et al. (1976) em pastagem natural com introdução de aveia e trevo vesiculoso. Já no tratamento sem adição de fosfatos as espécies introduzidas apresentaram pouca ou nenhuma participação na produção de forragem, indicando que o azevém e trevo vesiculoso são exigentes neste nutriente.

Na composição botânica da pastagem, foram identificadas 43 espécies, sendo que apenas $P$. notatum, P. plicatulum, E. ciliatum, Stylosanthes montevidensis, L. multiflorum, T. vesiculosum e o componente material morto apresentaram correlações com os eixos I e/ou II superiores a 50\%. Os eixos I e II respondem por 15,8 e 13,7\% da variação na contribuição percentual dos principais componentes da pastagem, respectivamente, totalizando $29,5 \%$ da variação.

Na figura 3, são apresentadas as trajetórias da composição botânica da pastagem no espaço de ordenação quando submetidos aos tratamentos. As trajetórias observadas (avaliações 1 a 6) representam a tendência da composicão florística (representada pela participação percentual de cada espécie) frente aos tratamentos e estações do ano. As espécies com maior correlação com os eixos de ordenação estão dispostas no plano espacial de acordo com suas coordenadas nestes dois eixos. De forma geral, a proximidade das trajetórias com determinadas espécies indicam a importância que esta tem na composição do referido tratamento, de acordo com o período de avaliação. As espécies anuais introduzidas tendem a apresentar alta correlação apenas durante a sua estação de crescimento.

Ciência Rural, v.35, n.1, jan-fev, 2005. 


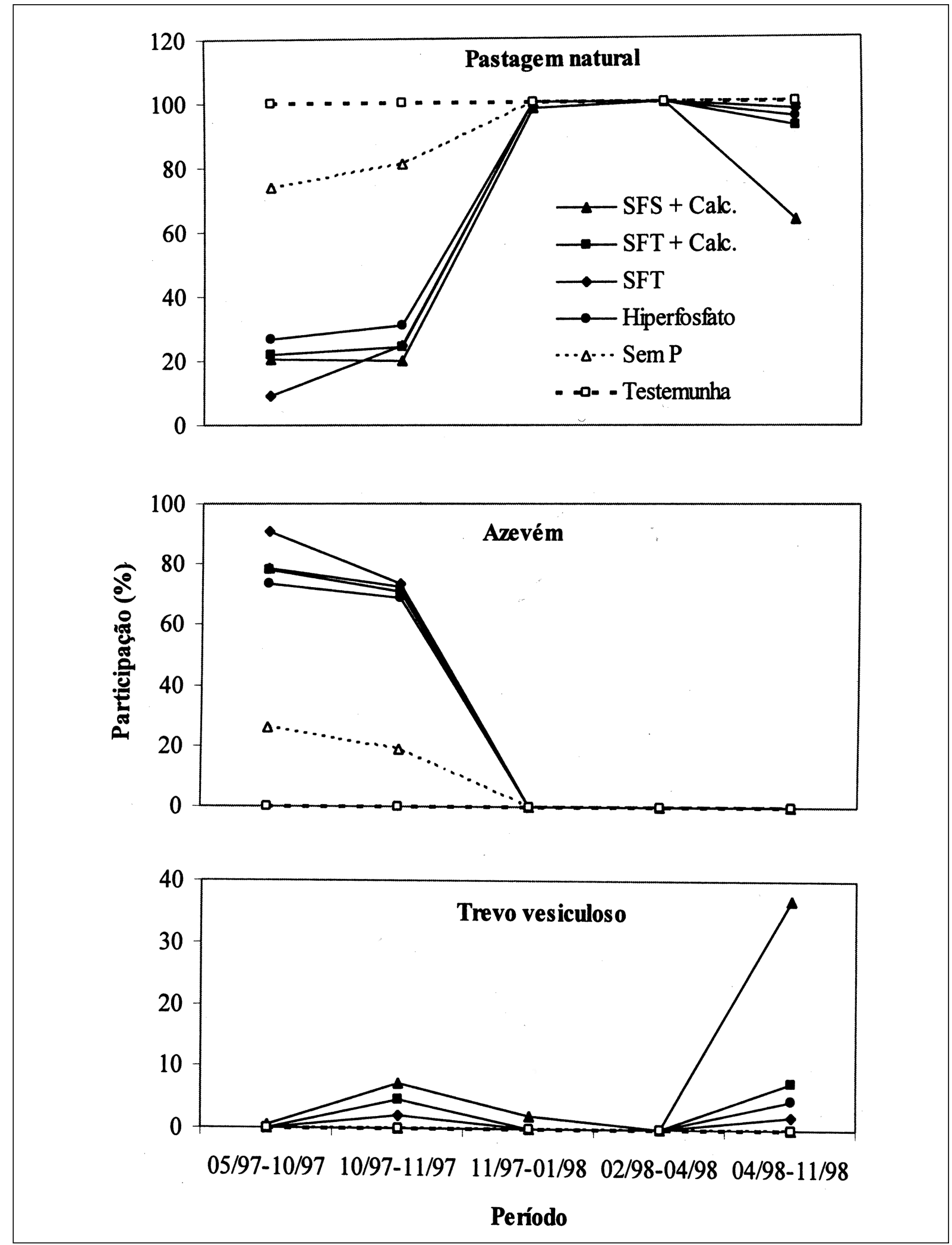

Figura 1- Participação percentual dos componentes: pastagem natural, azevém e trevo vesiculoso na produção de matéria seca de forragem nos cinco períodos de avaliação.

Ciência Rural, v.35, n.1, jan-fev, 2005. 


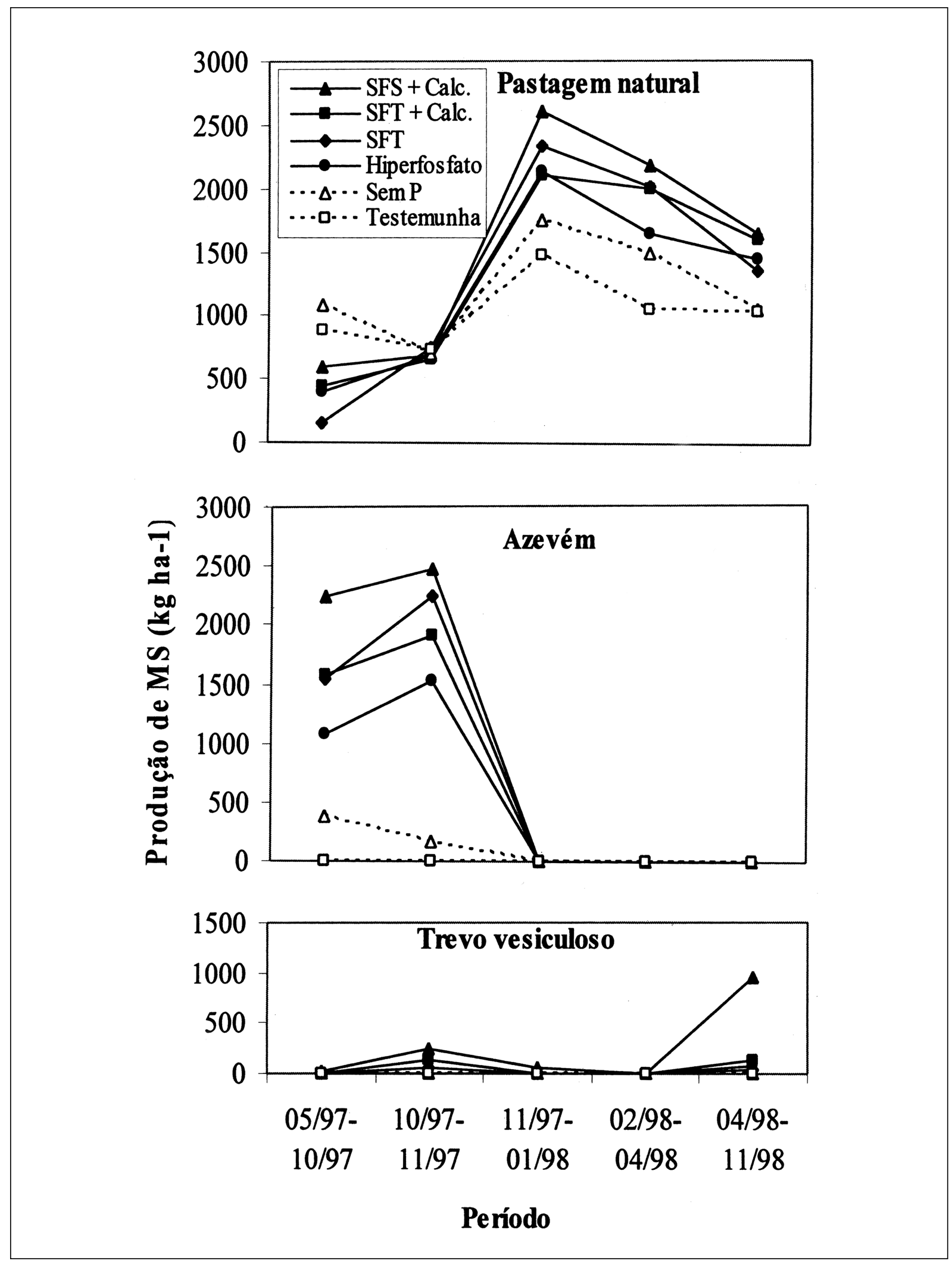

Figura 2- Produção de MS ( $\left.\mathrm{kg} \mathrm{ha}^{-1}\right)$ dos componentes da pastagem por período e tratamento.

Ciência Rural, v.35, n.1, jan-fev, 2005. 
Antes da semeadura das espécies e da aplicação dos tratamentos (período $1-\mathrm{V}$ ), pode-se observar que $\boldsymbol{P}$. notatum foi a espécie determinante da composição botânica, com elevada correlação em todos os tratamentos (Figura 3), sendo observada uma contribuição na MS de $61,3 \%$, na média dos tratamentos neste período. Na segunda avaliação (período 2-O), também realizada antes da semeadura, houve a tendência do componente material morto se destacar no plano de ordenação, sendo observada uma contribuição média dos tratamentos de $53,4 \%$ deste componente, podendo isto ser devido principalmente à avaliação ter sido realizada em período de ocorrência de geadas, o que favoreceu o crestamento das plantas. Nos dois primeiros períodos, a produção total da pastagem natural foi de $893,3 \mathrm{~kg} \mathrm{ha}^{-1}$ de MS, não sendo observada diferença na produção $(\mathrm{P}=0,05)$, o que demonstra a homogeneidade da área experimental.

$\mathrm{Na}$ terceira avaliação (período 3-I), realizada após o estabelecimento das espécies introduzidas, houve uma redução na contribuição de P. notatum de 29,3 para $25,8 \%$ na média dos tratamentos com aplicação de fósforo, respectivamente da segunda para a terceira avaliação da composição botânica (16/05 e 15/09/97). Estes tratamentos apresentaram elevada contribuição de $\mathbf{L}$. multiflorum na MS, nesta avaliação, variando de 73,4; 78,1; 78,8 e $91,0 \%$, respectivamente para hiperfosfato, SFT + calcário, SFS + calcário e SFT (Figura 1). Nos tratamentos em que não foram aplicadas fontes de fosfatos, houve um aumento da contribuição de $\boldsymbol{P}$. notatum da segunda para terceira avaliações, sendo de 31,7 para $57,5 \%$ no Sem $\mathrm{P}_{2} \mathrm{O}_{5}$ e de 33,3 para $36,4 \%$ na testemunha. Esses resultados podem ser observados na figura 1 (05/97-10/97), a qual demonstra que, quando da aplicação de fosfatos $\boldsymbol{L}$. multiflorum teve uma elevada contribuição, anteriormente citada, o que acabou exercendo competição sobre espécie da pastagem natural neste período. A produção total de MS de L. multiflorum variou de 1082; 1579; 2244 e

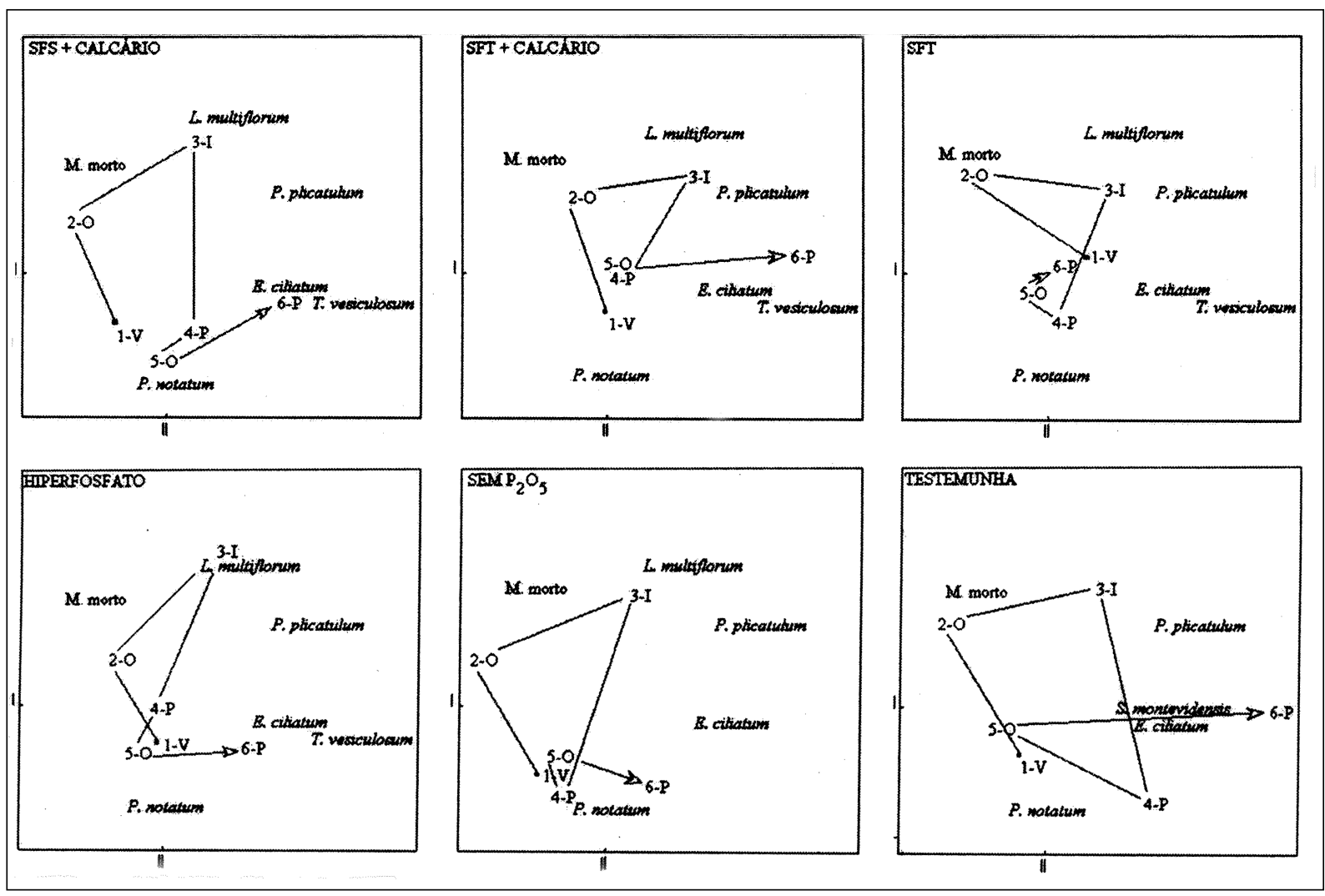

Figura 3- Diagrama de ordenação da composição botânica nos levantamentos botânicos realizados; os números de 1 a 6 representam os cortes e, as letras V, O, I e P representam as estações do ano (verão, outono, inverno e primavera, respectivamente). Os símbolos I e II representam os eixos de ordenação (I - abcissas e II - ordenadas). As espécies azevém (L. multiflorum); Paspalum plicatulum (P. plicatulum); Paspalum notatum (P. notatum); Eryngium ciliatum (E. ciliatum); trevo vesiculoso (T. vesiculosum); Stylosanthes montevidensis (S. montevidensis) e o componente material morto (M. morto) estão localizadas no espaço de ordenação segundo suas correlações com os eixos.

Ciência Rural, v.35, n.1, jan-fev, 2005. 
$1540 \mathrm{~kg} \mathrm{ha}^{-1}$ de MS, enquanto a produção das espécies nativas foi de 392; 443; 589 e $152 \mathrm{~kg} \mathrm{ha}^{-1}$ de MS (Figura 2), respectivamente para os tratamentos hiperfosfato, SFT + calcário, SFS + calcário e SFT.

No quarto (período 4-P) e quinto (período 5-O) levantamentos botânicos, todos os tratamentos tenderam à maior contribuição de $\boldsymbol{P}$. notatum $(67,5 \mathrm{e}$ $58,2 \%$ na média dos tratamentos para o quarto e quinto períodos), devido à baixa disponibilidade das espécies introduzidas nos respectivos levantamentos, como pode ser observada na figura 1 , para os períodos de 11/97-01/98 e 02/98-04/98, respectivamente. No sexto levantamento botânico (período 6-P), os tratamentos com adição de fósforo apresentaram uma contribuição na MS total média de 7,5;2,1; 4,7 e 33,9\% na participação de $\boldsymbol{T}$. vesiculosum, podendo ser observada sua distribuição percentual da MS no período (Figura 1), sendo verificada a maior participação no tratamento SFS + calcário. No período, foi observada uma produção de 957; 130; 30 e $71 \mathrm{~kg} \mathrm{ha}^{-1}$ de MS (Figura 2), respectivamente para SFS + calcário, SFT + calcário, SFT e hiperfosfato. Neste período, L. multiflorum não apresentou contribuição, já $\boldsymbol{P}$. notatum apresentou uma variação de 30,0 (SFT + calcário) a 75,7\% (Sem $\left.\mathrm{P}_{2} \mathrm{O}_{5}\right)$, nos demais $44,7 \%$ em média. A produção de MS da pastagem natural variou de 1040 (testemunha) a $1644 \mathrm{~kg} \mathrm{ha}^{-1}$ de MS (SFS + calcário) neste período (Figura 2).

Entre as espécies que determinaram a trajetória dos tratamentos (Figura 3), a contribuição de $\boldsymbol{P}$. notatum variou de 41,6 (SFT) a $58,8 \%$ (tratamento Sem $\mathrm{P}_{2} \mathrm{O}_{5}$ ) na média dos levantamentos, não sendo influenciada pelos tratamentos, discordando dos dados obtidos por FONTANELI \& JACQUES (1986), que observaram aumento da freqüência de $\boldsymbol{P}$. notatum quando da introdução de leguminosas na pastagem natural.

Para E. ciliatum houve variação na contribuição média dos levantamentos botânicos entre os tratamentos, de 15,0 (SFS) a 26,2\% (SFT), sendo observado $24,5 \%$ de média na testemunha, para os seis levantamentos. Analisando apenas do terceiro ao sexto levantamento, períodos onde houve competição entre espécies introduzidas e nativas, a variação percentual na contribuição desta espécie apresentou valores médios de: 30,$7 ; 25,4 ; 18,2$ e $24,4 \%$ para tratamentos com introdução de espécies. Na testemunha, esses valores foram de: 33,6; 63,3; 20,0 e 30,0\% nos mesmos períodos. Este resultado mostra que a maior participação de $\boldsymbol{E}$. ciliatum, observada na testemunha, deve estar relacionada com a menor competição entre espécies, comparada aos tratamentos com introdução de espécies, nos quais há uma maior competição por área, não propiciando o aumento de sua freqüência na pastagem. Esse resultado concorda com os obtidos por FONTANELI \& JACQUES, (1986); SILVA \& JACQUES, (1993) e CASTILHOS \& JACQUES, (2000), que observaram, dentre outras espécies, diminuição da participação de Eryngium sp. com a introdução de espécies, aplicação de calcário e adubação NPK em uma pastagem natural.

$\mathrm{Na}$ testemunha, apenas foi observada a participação de Stylosanthes montevidensis, leguminosa nativa, no decorrer das avaliações com $1,7 \%$ de contribuição na MS no último período de avaliação. Resultados mais evidentes quanto à modificação da composição botânica podem não ter sido observados neste trabalho porque segundo BARRETO et al. (1986), em geral, são necessários alguns anos para que se evidenciem os efeitos dos fertilizantes sobre a dinâmica das espécies dos campos naturais.

\section{CONCLUSÃO}

A introdução de espécies forrageiras de crescimento inverno-primaveris, associadas ou não à adubação fosfatada e calagem, não provocaram mudanças significativas na composição botânica da pastagem natural no período de tempo estudado.

\section{REFERÊNCIAS BIBLIOGRÁFICAS}

BARRETO, I.L. et al. Melhoramento e renovação de pastagens. In: PEIXOTO, A.M. et al. (Ed.). PASTAGENS: FUNDAMENTOS DE EXPLORAÇÃO RACIONAL, 1986, Piracicaba. Anais... Piracicaba : FEALQ, 1986. p.295-309.

BOLDRINI, I.I. Campos do Rio Grande do Sul: caracterização fisionômica e problemática ocupacional. Porto Alegre : UFRGS, 1997. p.1-39. (Boletim do Instituto de Biocências, 56).

CARÁmbUla, M. Pasturas naturales mejoradas. Montevideo: Hemisferio Sur, 1997. 524p.

CASTILHOS, Z.M.S.; JACQUES, A.V.A. Pastagem natural melhorada pela sobressemeadura de trevo branco e adubação. Pesquisa Agropecuária Gaúcha, Porto Alegre, v.6, n.1, p.19-25, 2000.

COMISSÃO DE FERTILIDADE DO SOLO - RS/SC. Recomendação de adubação e calagem para os estados do Rio Grande do Sul e Santa Catarina. 3.ed. Passo Fundo : SBCS/ NRS/EMBRAPA/CNPT, 1994. 224p.

FONTANELI, R.S.; JACQUES, A.V.A. Composição botânica de uma pastagem natural da depressão central do Rio Grande do Sul submetida a tratamentos de introdução de espécies temperadas. In: REUNIÃO ANUAL DA SOCIEDADE BRASILEIRA DE ZOOTECNIA, 23., 1986, Campo Grande. Anais... Campo Grande : SBZ, 1986. p.234. 
GATIBONI, L.C. et al. Influência da adubação fosfatada e da introdução de espécies forrageiras de inverno na oferta de forragem de pastagem natural. Pesquisa Agropecuária Brasileira, Brasília, v.35, n.8, p.1663-1668, 2000.

GATIBONI, L.C. et al. Superphosphate and rock phosphates as P-source for grass-clover pasture on a limed acid soil of Southern Brazil. Communications in Soil Science and Plant Analysis, New York, v.42, n.17-18, p.1-12, 2003.

GOMES, K.E. et al. Efeito de ofertas de forragem, diferimentos e adubações sobre a dinâmica da pastagem natural. II: Composição florística. In: REUNIÃO DO GRUPO TÉCNICO EM FORRAGEIRAS DO CONE SUL - ZONA CAMPOS, 17., 1998, Lages. Anais... Lages : Epagri/UDESC, 1998. p.137.

IBGE - Fundação Instituto Brasileiro de Geografia e Estatística. Censo agropecuário: Rio Grande do Sul - 1996. Capturado em 10 mar. 2003. Online. Disponível na Internet: http://www.ibge.org/ informacoes/censo96/agro/43/D43-t01.htm.

MACEDO, W.; GONÇALVES, J.O.N. Resposta da cultura de trevo branco (Trifolium repens) cv. Bagé à calagem e à adubação fosfatada e potássica. Revista Brasileira de Ciência do Solo, Campinas, v.4, n.1, p.39-44, 1980.

MACEDO, W. et al. Melhoramento de pastagem natural com fosfatos e introdução de leguminosas em solo da fronteira oeste do Rio Grande do Sul. Revista Brasileira de Ciência do Solo, Campinas, v.9, n.3, p.231-235, 1985.

NABINGER, C. Técnicas de melhoramento de pastagens naturais no Rio Grande do Sul. In: SEMINÁRIO SOBRE PASTAGENS "DE QUE PASTAGENS NECESSITAMOS", 1980, Porto Alegre, RS. Anais... Porto Alegre : FARSUL, 1980. p.28-58.

PILLAR, V.D.P. Multivariate exploratory analysis and randomization testing with MULTIV. Coenoses, Gorizia, v.12, n.2-3, p.145-148, 1997.

PODANI, J. Multivariate data analysis in ecology and systematics. The Hague : SBP, 1994. 180p.

RHEINHEIMER, D.S. et al. Situação da fertilidade dos solos do Rio Grande do Sul. Santa Maria : UFSM, Departamento de Solos, 2001. 41p. (Boletim Técnico, 2).

SCHOLL, J.M. et al. Improvement of pastures by direct seeding into native grass in Southern Brazil with oats, and with nitrogen supplied by fertilizer or arrow leaf clover. Turrialba, San Jose, v.26, n.2, p. 144-149, 1976.

SILVA, J.L.S.; JACQUES, A.V.A. Disponibilidade de forragem de uma pastagem natural sobressemeada com leguminosas perenes de estação quente. Revista da Sociedade Brasileira de Zootecnia, Viçosa, v.22, n.6, p.920-929, 1993.

STRECK, E.V. et al. Solos do Rio Grande do Sul. Porto Alegre: UFRGS, 2002. 107p.

TOTHILL, J.C. et al. BOTANAL - A comprehensive sampling and computing procedure for estimating pasture yield and composition. 1. Field sampling. Tropical Agronomy Technical Memorandum, Camberra, v.78, p.1-24, 1992. 